\title{
New approaches to customized employment: Enhancing cross-system partnerships
}

\author{
Rebecca S. Salon ${ }^{\mathrm{a}, *}$, Nancy Boutot ${ }^{\mathrm{a}}$, Keith Ozols ${ }^{\mathrm{b}}$, Beth Keeton ${ }^{\mathrm{c}}$ and Janet Steveley ${ }^{\mathrm{c}}$ \\ ${ }^{a}$ LEAD Center, National Disability Institute, Washington, DC, USA \\ ${ }^{\mathrm{b}}$ Workforce and Youth Manager, Oregon Vocational Rehabilitation, Salem, OR, USA \\ ${ }^{\mathrm{c}}$ Griffin-Hammis Associates, Atlanta, GA, USA
}

Revised/Accepted November 2018

\begin{abstract}
.
BACKGROUND: Over the last 15 years, customization has emerged nationally as a powerful job creation strategy for a wide variety of people, including those who experience the most significant disabilities or other barriers to employment. Following the passage of the Workforce Innovation and Opportunity Act of 2014 (WIOA), the state of Oregon partnered with the National Center on Leadership for the Employment and Economic Advancement of People with Disabilities (LEAD Center) to explore a new approach to Customized Employment (CE) called Guided Group Discovery (GGD) (2018), in which multiple systems/agencies can support youth and adults to achieve an employment outcome.

OBJECTIVE: This paper explores approaches to bring Guided Group Discovery to scale through cross-system partnerships, leveraging Pre-Employment Transition Services (Pre-ETS) and funding to improve employment outcomes for youth.

METHODS: During school year 2017-18, Oregon Vocational Rehabilitation(VR) and the LEAD Center created a partnership to modify and implement the LEAD Center's Guided Group Discovery curriculum, with support from six school districts, to make it more accessible to youth with disabilities that were benefiting from their Pre-Employment Transition Services. This project also leveraged the resources of the workforce system, through partnerships with local American Job Centers (AJCs). RESULTS: The facilitators of GGD in the Oregon pilot sites received unanimous feedback from student participants that the GGD process had real-life impact. Students indicated that they had a better understanding of the myriad of adult service agencies available to them, as well as how to contact and connect with them. They reported that they now felt comfortable with what they have to offer an employer and knew how to communicate that to potential employers. Schools will be continuing to implement GGD, some starting with younger students, and new schools will be initiating GGD pilots in the 2018-2019 school year.

CONCLUSIONS: Guided Group Discovery bridges the gap between Customized Employment and Pre-ETS services, providing an efficient process and structure for coordinating transition services. GGD is easily adapted to a school schedule and can be embedded within the framework of existing classes, clubs, afterschool programs, and summer youth employment programs. Students participating in GGD classes not only learn more about themselves, their own skills and conditions for success. They also gain confidence and become familiar with the services and supports available from adult service agencies.
\end{abstract}

Keywords: Youth employment, customized employment, discovery, competitive integrated employment, transition, preemployment transition services

*Address for correspondence: Rebecca S. Salon, LEAD Center Project Director, National Disability Institute, 1667 K Street, NW, Suite 480, Washington, DC 20006, USA. Tel.: +1 240205 0289; E-mail: rsalon@ndi-inc.org.

\section{Background}

Over the last fifteen years, customization has emerged nationally as a powerful job creation strategy for a wide variety of people, including those 
who experience the most significant disabilities or other barriers to employment. Following the passage of the Workforce Innovation and Opportunity Act of 2014 (WIOA), the state of Oregon partnered with the National Center on Leadership for the Employment and Economic Advancement of People with Disabilities (LEAD Center) to explore a new approach to Customized Employment (CE) called Guided Group Discovery (GGD) (2018), in which multiple systems/agencies can support youth and adults to achieve an employment outcome. Many states are working to develop partnerships, policies, procedures, and funding streams to support Customized Employment (CE). Leadership in Oregon's Vocational Rehabilitation Agency saw an opportunity to use Pre-Employment Transition Services (Pre-ETS) funding and Guided Group Discovery to benefit youth with disabilities statewide. Defining interagency roles and responsibilities has proven both crucial and challenging for many states, as agencies work to identify, define, and align complementary, non-duplicative services within the parameters of their stated missions and activities. The opportunities and challenges for interagency collaboration are particularly compelling for transition services because the stakes are high. Historically, students have been served solely by school systems. However, decades of research has shown a powerful correlation between early work exposure and experiences for youth, and competitive, integrated employment outcomes as adults (Citron et al., 2008; Fesco et al., 2008; Luecking \& Luecking, 2015; Wehman et al., 2015). VR agencies striving to establish partnerships with schools, workforce systems, post-secondary education, community employment providers, and others must work to align Pre-ETS with CE. Staff across systems need to understand how CE fits within Pre-ETS, how CE can be incorporated within educational planning for younger students, and how $\mathrm{CE}$ can be expanded to reach youth beyond those who experience the most significant impact of disability.

Customized Employment was first defined in 2001, not long after the beginning of the Office of Disability Employment Policy (ODEP) at the U.S. Department of Labor. However, even though ODEP has maintained a commitment to CE after introducing it in 2001, and it has been implemented broadly in the field, CE was not included in the workforce law until 2014, when it was included in WIOA.

\subsection{Why Guided Group Discovery}

Discovery is the backbone of CE and is always the first step in the CE process. Discovery illuminates the critical skills, interests, support needs, and ideal conditions of employment that ultimately serve as the foundation for negotiating and creating work that "fits" for an individual. Equally important, though, is the connection of ideal conditions of employment with real-life work. Too frequently, students either rotate through pre-established work experience sites, which may or may not align with their unique skills and interests, or are left out of the work equation altogether. Employment may be covered as a part transition planning in an Individualized Education Plan (IEP) but employment planning may not be backed up by any functional, meaningful work opportunities and/or a well-developed Discovery profile.

Guided Group Discovery bridges the gap between $\mathrm{CE}$ and Pre-ETS services, providing an efficient process and structure for coordinating transition services. GGD is easily adapted to a school schedule and can be embedded within the framework of existing classes, clubs, afterschool programs, and summer youth employment programs. Students participating in GGD classes not only learn more about themselves, their own skills, and conditions for success, but they become familiar with the services and supports available from adult service agencies.

Students completing GGD use the information gleaned to guide IEP or other individual plan development. It also supports and empowers them to advocate for real work experiences. GGD opens the door to paid work that matches who they are and connects them with adult agencies that can support them in negotiating and/or connecting to work that meets their needs and the needs of an employer. Representatives from schools, Vocational Rehabilitation, American Job Centers, and employment provider agencies all can play critical roles in facilitating the GGD classes and supporting individual youth and adults.

\subsection{Why create alternatives to traditional facilitated Discovery?}

Guided Group Discovery is a viable option for some, but not all, transitioning students. Some students, particularly those with the most significant disabilities or those who do not enjoy working within a group, might benefit more from an individualized, facilitated approach to Discovery. Other youth, who 
want to control their entire Customized Employment planning process, may want to pursue Self-Guided Discovery (SGD) (2018). For other students, however, GGD serves as an excellent starting place for determining ideal conditions of employment, and is easily adapted to a structured school schedule and setting.

\subsection{Who benefits from Guided Group Discovery?}

Characteristics of students likely to benefit from GGD include those who:

$\checkmark$ Do well in group settings and enjoy group interaction;

$\checkmark$ Have some life/work experiences from which to draw information;

$\checkmark$ Can seek input from others;

$\checkmark$ Can, with support, translate typical activities into potential interests, skills, and conditions of employment; and

$\checkmark$ Advocate for themselves with teachers, adult service providers and potential employers.

For example, Michael, a student in his junior year of high school in one of LEAD Center's pilots, participated in Guided Group Discovery. GGD helped Michael see how his interests and skills could lead to a career in the culinary field. The AJC Youth Coordinator, a co-facilitator of the GGD process, connected Michael with one of the AJC's Business Representatives. Together, they supported Michael in exploring careers in the culinary field, using informational interviews. As a result, Michael connected with the owner of a new gourmet hot dog business in his small community. The team was able to arrange a six-week paid summer work experience once school was out for the summer, funded through the AJC Youth Program. Michael did well, learned a lot, and was offered part-time paid employment at the end of the summer work experience. During his last year of school, while working part-time, he was able to advocate for himself at his IEP meeting to attend culinary school the following year. He learned how both the American Job Center and Vocational Rehabilitation could support him in this goal and co-enrolled in both programs prior to leaving school.

\subsection{Implementation in Oregon}

Oregon's VR took the lead on this statewide program. Their general VR program, which is not combined with the blind program as in some other states, has 126 Vocational Rehabilitation Counselors housed in 15 branch offices and 28 outstations across the state. They work with the 197 school districts, 165 of which have high schools. The other 32 are too small to sustain a high school so that students in smaller middle schools transfer to attend neighboring high schools.

Oregon VR administers a Youth Transition Program (YTP), which is an intergovernmental partnership between VR and 120 local school districts across the state. YTP provides an array of enhanced transition services to students with disabilities including Pre-ETS, information and referral to local VR offices, and many other VR Services. Oregon VR also collaborates with the Oregon Department of Education (ODE) on a program called the Transition Technical Assistance Network (TTAN). The TTAN is a network of eight professional staff called Transition Network Facilitators, co-funded by VR and ODE. The goal of the TTAN is to provide technical assistance to local school districts in Oregon on best practices in Transition services.

The project started with training of the TNFs statewide during the summer of 2017. As part of the training on GGD, CE and Discovery, the TNFs provided suggestions for creating youth-specific content to engage youth. Their input informed the creation of a Youth Field Test version of both the GGD manual and participant workbook, developed collaboratively by LEAD Center, Oregon VR and Griffin-Hammis Associates. Using the TNFs as leaders in the project strengthened the project, given their background as transition classroom teachers. Oregon's VR and Education departments recruited schools through a competitive process. Schools were eager to apply because of TTAN's reputation and credibility as a program funded and supported by the state's departments of education and VR. The TNFs also encouraged schools to apply, and were central to training teachers and co-facilitating lessons with school staff.

Oregon VR, with support from the LEAD Center, solicited application from existing districts that were running YTP sites, for potential participation is a statewide GGD pilot. The requirements included a commitment by participating districts that they would allot enough time in their syllabus to accommodate the 10 lessons. More than 15 school districts responded to the recruitment. Ultimately, six school districts were chosen for the initial pilot. The districts included urban, semi-rural and very rural locations. 
Upon selection, the local TNFs coordinated the development of a local plan for implementation of the GGD curriculum, in collaboration with the LEAD Center, VR staff, local staff from the American Job Center, and the school district administrators. Once selected, LEAD Center conducted facilitator training with TNFs and teachers, recorded a webinar on GGD for AJC and VR staff who could not attend the training, and presented on Customized Employment, Discovery and the GGD pilot project at the statewide Oregon Transition Conference.

Through the curriculum modification process, TNFs and school staff recommended that the original five (5) sessions, each lasting 1.5-2 hours, should be divided up into 10, 45-60 minute sessions. That adjustment made it easier to integrate GGD into the normal school day in a standard class schedule. TNFs who participated in the training also assisted the LEAD Center in adapting the GGD curriculum materials to be more youth-friendly, making lessons more interactive, adding more hands-on learning that was personally relatable for young participants, adapting language, adding activities, and changing examples to be relevant to youth with little or no work history.

\section{Results}

The facilitators of the Oregon pilot sites received unanimous feedback from student participants that the GGD process had real-life impact. Students indicated that they had a better understanding of the myriad of adult service agencies available to them, as well as how to contact and connect with them. They reported that they now felt comfortable with what they have to offer an employer and knew how to communicate that to potential employers. All facilitators spoke of the power of watching the students practice and give their networking pitches, witnessing their confidence grow over time. The students learned how to talk about themselves and their disabilities in a positive manner and began to define and describe themselves differently, as a result. One student said that graduation and employment no longer felt like a "big black hole." He now understood how to find businesses that aligned with his skills and interests, and how to speak to employers and positively represent himself during interviews.

All students were given a pre-test and post-test to measure their knowledge on topics such as knowing the services for which they were eligible and their comfort level on job interviews. LEAD Center also tracked individual responses as to how well students felt the Guided Group Discovery process worked for them. Although data is still being collected, in early data, students reported an increase in their knowledge of Vocational Rehabilitation, WorkSource, Community Developmental Disabilities programs, mental health services, as well as work incentives, benefits counseling, services through Centers for Independent Living, and more. In preliminary data, students reported that developing a networking pitch, conducting informational interviews, and identifying their conditions of employment were most helpful.

Students were asked the following questions, listed below with some responses: How has the Guided Group Discovery process helped you?

- GGD has helped me find resources that weren't there before, like VR.

- It made me more responsible and helped me work on the future.

- It helped me learn more about jobs.

- I now have more information to work with.

- It showed how to get my new job.

- I discovered more opportunities.

Which parts did you find most useful?

- Identifying skills, interests, tasks and positive personality traits.

- Discussion about job opportunities and getting the teacher's feedback.

- How to do an interview and how to get paid good.

- Who I could ask for help if I were to need a job, and the help we can get to find a job.

- Talking about my past jobs.

- Learning about paid jobs.

- Setting goals to find jobs.

Some facilitators found the lesson on skills and traits to be particularly powerful and a tremendous confidence booster for their students. One facilitator said that she "saw the lights start to come on after we talked about skills. It's always tough to get students to list skills, they tend to just say what they do. But everyone got really involved in helping each other see their positive personality traits and skills that go into their hobbies and sports. Participants went from saying, 'I play soccer' to identifying 30 different skills and team-building traits associated with playing soccer and now listing all these things on a resume." They watched the "students' smiles get 
bigger and bigger as the other participants identified these traits for them - communicating under stress, team-building, executing plans, etc."

Another participant who reported that she did "nothing" finally shared some of her knitting, and the other group members helped her identify a list of 30 things she did well as a part of the knitting. This was a huge breakthrough for that student.

\section{Summary and conclusion}

During school year 2017-18, Oregon Vocational Rehabilitation and the LEAD Center created a partnership to modify and implement the LEAD Center's Guided Group Discovery curriculum, with support from six school districts, to make it more accessible to youth with disabilities that were benefiting from their Pre-Employment Transition Services. There were five key questions that these partners wanted to explore through a statewide pilot project. They were: (1) could Guided Group Discovery meet some, or all, of the five required Pre-ETS services, as outlined in the Workforce Innovation and Opportunity Act (WIOA); (2) would Guided Group Discovery create greater access to American Job Centers for students with disabilities; (3) would there be a benefit to both rural and urban school districts implementing the curriculum; (4) how would the students respond to the curriculum; and finally (5) would this result in positive employment and post-secondary education outcomes. While it is early in the evaluative process, the initial evidence shows very positive results and was an important learning experience for all of the partners.

As noted above, most of the initial findings have been very positive. Upon completion of the pilot, partners interviewed the YTP staff that helped facilitate the curriculum. One of the interviewees was from Nyssa High School, a very rural school on the border of Oregon and Idaho. Nyssa is a traditional 9th through 12th grade high school with 329 students. Of that student body, only $15 \%$, or 49 , of the students experience a disability. Nyssa, as a community, is also very rural and small, with a total population of 3,267. Response to questions about the benefits of Guided Group Discovery illustrate how it helped connect people to small community resources and its potential to foster more community engagement. When asked about how the curriculum benefited them, the YTP staff at Nyssa explained that:
"I do believe partnerships were enhanced between the students and workforce. After the program, they had a much better understanding that there are agencies that want to help them succeed and that they are not on their own. I am finding the returning students are much better at advocating for their needs and coming to me with good questions about our community supports. The schools benefited as they, as a whole, were unaware of all the community supports out there and feel their students now have a better understanding of how to get help when they aren't in school. I do feel, with more time and inviting more guest speakers, this curriculum will be a strong bridge between my school and the community workforce supports."

When asked if Guided Group Discovery was a good way to implement or address Pre-ETS, they responded that it "was an excellent platform for addressing Pre-ETS. Our guided group discussions and activities covered all the Pre-ETS (except work-based learning experiences) either directly or indirectly."

When asked about how the students responded to the curriculum, the responses were very encouraging. For example, one responder noted:

"I really feel the groups of students participating felt GGD was a safe place to admit they struggle, were unsure, and to ask questions. The students were very quick to help each other. We involved a lot of humor... adding humor and stories seemed to help a lot. I noticed students I was having trouble reaching are now asking to come visit me. The safe space of GGD and the ownership I encouraged the students to take, plus humor, brought down a lot of walls the students perceived were there. I plan to implement this curriculum yearly, but over a longer duration of time, so I can have guest speakers and do more activities. I also supply food at all meetings and treated it more like a club than a class...I feel this was really important as all my students participated, and my poor-attendance students increased their attendance on the days they had GGD. Two students at high risk of dropping out are coming to me regularly, are participating in their senior year, and are really applying themselves to finding jobs, and looking at their place in their community."

Another school that participated in the pilot, located in the town of Marcola, is about 17 miles 
away from Eugene, the second most populated city in Oregon. This pilot site had similar good things to report about Guided Group Discovery. In their case, there was a fortuitous partnership because the YTP staff member was jointly funded by VR and the WIOA Title I Youth Formula program, working halftime for each. This staff member reported that Guided Group Discovery helped him deliver services that met the needs of both programs. After completing the 10 lessons, all of the students that participated at the Marcola site had developed blueprints for employment. Their dedicated VR Counselor also had been to the school to participate in the project and saw the value in these blueprints. With the information outlined in the blueprint, she understood how she could build on the previous career-related work completed at the school.

Students cited valuable information they gained from the curriculum, which included their networking pitch, the ability to identify job matches, knowing the difference between preferences and conditions, and knowing their needed accommodations. A highlight from Marcola was that a student used his "networking pitch" to articulate his skillset at a local restaurant on his way home from school one day, which resulted in a job offer that led to competitive integrated employment for the student.

\subsection{Next steps}

Moving forward, Oregon VR will continue to offer Guided Group Discovery as one of their Pre-ETS programs, with TNFs training school staff to facilitate in their classes. Partners also will explore using this curriculum to deliver Pre-ETS in other group settings. Most importantly, VR, school and workforce partners will track the students participating in Guided Group Discovery, to determine the extent to which it continues to help them in identifying interests, articulating needed supports, and teaching them how to cultivate their own allies in finding a meaningful job.

\subsection{Information on initial training of TNFs}

A Youth-specific version of GGD, incorporating suggestions from the Oregon and Philadelphia pilots, will be made available for download from the LEAD Center at www.leadcenter.org.

Oregon systems will continue to build their partnerships to implement GGD, in collaboration with the state's vocational rehabilitation and partners from the schools and workforce systems. Planned activities include:

1. Co-facilitation of GGD sessions between schools, workforce, vocational rehabilitation, and other agencies as needed (e.g., Community Rehabilitation Programs, Corrections, Behavioral Health, Developmental Disabilities).

2. Development of an agreed-upon process for data sharing. The State of Oregon is working on a Memorandum of Understanding (MOU) for data sharing, but teams will likely also need local interagency agreements and consents for the release of information.

3. Enrolling or co-enrolling participants for GGD sessions from key programs (school, workforce, vocational rehabilitation via Pre-ETS data tracking);

4. Asking youth for their voluntary agreement to participate in follow-up, so that TNFs can follow up directly with participants post-school. (If youth are under age 18, TNFs will solicit parental permission.)

5. Arranging for Transition Network Facilitators to collect data on outcomes for participants of Guided Group Discovery to include:

- Data elements on participating students (name, ID ethnicity, disability, date Pre-ETS started).

- Information on enrollment in various services (AJC, VR if the student chooses to apply, other).

- The impact of the GGD Blueprint for Employment on IEPs, IPEs, and other employment plans.

- Leveraged resources (across systems plus benefits counseling, independent living services, etc.).

- Customized job placements based on information in Employment Blueprints.

\section{Acknowledgments}

The authors would like to thank Christopher Button, Ph.D., Supervisor, Workforce Systems Policy Team, Office of Disability Employment Policy, U.S. Department of Labor for her vision and support of this project, and all of the talented associates from Griffin-Hammis Associates that supported the work of the LEAD Center, Cary Griffin, Bob Niemiec and Cory Smith. 


\section{Conflict of interest}

None to report.

\section{References}

Citron, T., Brooks-Lane, N., \& Crandell, D. (2008). A revolution in the employment process of individuals with disabilities: Customized employment as the catalyst for system change. Journal of Vocational Rehabilitation, 28, 169-179.

Fesko, S., Varney, E., DiBiase, C., \& Hippenstiel, M. (2008). Effective partnerships: Collaborative efforts that support customized employment. Journal of Vocational Rehabilitation, 28(3), 159-168.

LEAD Center. (2018). Guided Group Discovery Facilitator Guide, Participant Workbook and PowerPoint. National Disability
Institute, Washington, D.C. Retrieved from http://leadcenter. org/resources/tool-manual/guided-group-discovery-resources -introduction-and-course-participant-workbook-and-facilitat or-guide.

LEAD Center. (2018). Self-guided Discovery facilitators guide: Helping people discover their own path to employment. Washington, D.C.: National Disability Institute. Retrieved from http://leadcenter.org/resources/tool-manual/self-guideddiscovery-facilitators-guide-helping-people-discover-theirown-path-employment.

Luecking, D. M., \& Luecking, R. G. (2015). Translating research into a seamless transition model. Career Development and Transition for Exceptional Individuals, 38(1), 4-13.

Wehman, P., Sima, A.P., Ketchum, J., West, M.D., Chan, F., \& Luecking, R. (2015). Predictors of successful transition from school to employment for youth with disabilities. Journal of Occupational Rehabilitation, 25(2), 323-334. 